\title{
Revision of the Neotropical species of Empididae (Diptera) described by Mario Bezzi. IX. The species described in Atrichopleura Bezzi and the description of a new species
}

\author{
José Albertino Rafael ${ }^{1}$ \\ ${ }^{1}$ Coordenação de Entomologia, Instituto Nacional de Pesquisas da Amazônia, Caixa Postal 478, 69011-970, Manaus-AM, Brazil. jarafael@inpa.gov.br
}

\begin{abstract}
Revision of the Neotropical species of Empididae (Diptera) described by Mario Bezzi. IX. The species described in Atrichopleura Bezzi and the description of a new species. Four Neotropical species of Empididae described by Bezzi in Atrichopleura Bezzi, 1909 are redescribed: A. crassa (lectotype, pres. desig.), A. hirtipes (lectotype, pres. desig.), A. nitida (lectotype, pres. desig.), A. schnusei (lectotype, pres. desig.). Atrichopleura bezzii sp. nov. is described from among syntypes of $A$. schnusei.
\end{abstract}

KEYWORDS. Atrichopleura bezzii; Neotropical Region; taxonomy.

RESUMO. Revisão das espécies neotropicais de Empididae (Diptera) descritas por Mario Bezzi. IX. As espécies descritas em Atrichopleura Bezzi e a descrição de uma nova espécie. São redescritas quatro espécies neotropicais descritas em Atrichopleura Bezzi, 1909: A. crassa (lectótipo, pres. desig.), A. hirtipes (lectótipo, pres. desig.), A. nitida (lectótipo, pres. desig.), A. schnusei (lectótipo, pres. desig.). Atrichopleura bezzii sp. nov. é descrita a partir de síntipos de A. schnusei.

PALAVRAS-CHAVE. Atrichopleura bezzii; região Neotropical; taxonomia.

This work continues the redescription of Neotropical species described by Mario Bezzi in the family Empididae. Atrichopleura Bezzi belongs to the tribe Hilarini (subfamily Empidinae), a tribe that has been characterized in Sinclair \& Cumming (2006) and in a recent contribution (Rafael 2011). The genus contains 26 species distributed in different regions of the Southern Hemisphere (Neotropics, Afrotropics and Australasian). In the Neotropical Region, 23 species are recorded, all from South America (Yang et al. 2007).

\section{MATERIAL AND METHODS}

Bezzi (1909) described Atrichopleura including four Neotropical species whose types are deposited in the Staatlisches Museum für Tierkunde (SMT), Dresden, Germany. All the types are redescribed herein. The terminology is according to McAlpine (1981), as presented in the first paper of this series (Rafael \& Ale-Rocha 1995), now updated after Cumming \& Wood (2009). Setae on symmetrical structures that are represented in dorsal view are indicated only on one side whenever the same pattern is repeated on the other side. In the lists of material examined, supplementary information that was omitted from the labels is enclosed in brackets.

\section{RESULTS}

\section{Atrichopleura Bezzi}

Diagnosis. Members of Atrichopleura are characterized by the following combination of characters: dichoptic in both sexes; frons with bristles; postpedicel equal to or longer than stylus, proboscis vertical and short, usually shorter than height of head; laterotegite without setae; costal vein reaching the apex of the wing, Sc vein incomplete or nearly so; vein $\mathrm{R}_{1}$ distally swollen; pterostigma located at the apex of vein $\mathrm{R}_{1}$; vein $\mathrm{R}_{4+5}$ simple; legs simple, without long setae in female specimens; proctiger complex with the cercus, hypoproct and subepandrial sclerite with clasping function; keel-shaped hypandrium on the posterior margin and covering the phallus.

\section{Atrichopleura crassa Bezzi}

(Figs. 1-12, 49)

Atrichopleura crassa Bezzi, 1909: 359; Melander, 1928: 134; Collin, 1933: 195, 196 (cit); Smith, 1967: 31 (cat), Yang et al. 2007: 203 (cat).

Diagnosis. Black with dense grey pruinosity. Frons very wide and subquadrate. Postcranial setae more robust in the upper half. Proboscis short and straight. Scutum with longitudinal band of darker pruinosity. Two pairs of scutellar setae. Fore basitarsomere thicker than tibia in male specimens. Sc vein incomplete. Vein $\mathrm{A}_{1}$ evanescent. Halter pale yellow.

Redescription. Lectotype male (pres. desig.). Body 2.5 $\mathrm{mm}$, wing $2.7 \mathrm{~mm}$ long.

Head (Fig. 1) dichoptic. Frons, face and postcranium dark brown to black with dense grey pruinosity. Frons (Fig. 2) wider than ocellar triangle, slightly wider than high, with three short proclinate lateral setae. Face glabrous, slightly higher than wide, as wide as frons. Palpus (Fig. 1) yellow, curved upward, with swollen and glabrous apex. Proboscis straight, shorter than 
head height, with shiny black labrum, other parts brown. Ocellar triangle slightly protruding, with divergent anterior ocellar setae and 2-3 reduced posterior setae. Ocelli reddish, glassy. Antenna matte black and velvety; postpedicel two times longer than length of scape and pedicel combined, and two times longer than stylus. Postcranium (Fig. 3) upper half with robust black setae, lower half with slender and clear setae; upper setae biserial, with vertical setae subequal to anterior and ocellar setae; lower setae multiserial. Gena and postgena with long slender clear setae.

Thorax dark brown to black, densely grey pruinose. Scutum (Fig. 4) with narrow longitudinal bands of brown pruinosity between acrostichal and dorsocentral setae and wider and shorter bands between dorsocentral and supra-alar setae. Chaetotaxy: 2 distinct, clear, lateral antepronotal setae; 4-5 postpronotals (1 more robust and black); 2-3 proepisternals, slender and clear; several proepimerals, short and clear; 8-9 uniseriate acrostichals; 10 uniseriate dorsocentrals ( 2 posterior setae more robust); 1 intra-alar presutural; 1 supra-alar presutural; 3 supra-alar postsuturals, posterior one more robust; 1 postalar; 3 notopleurals; 2 scutellars, apical more robust and convergent (seen in female specimen).
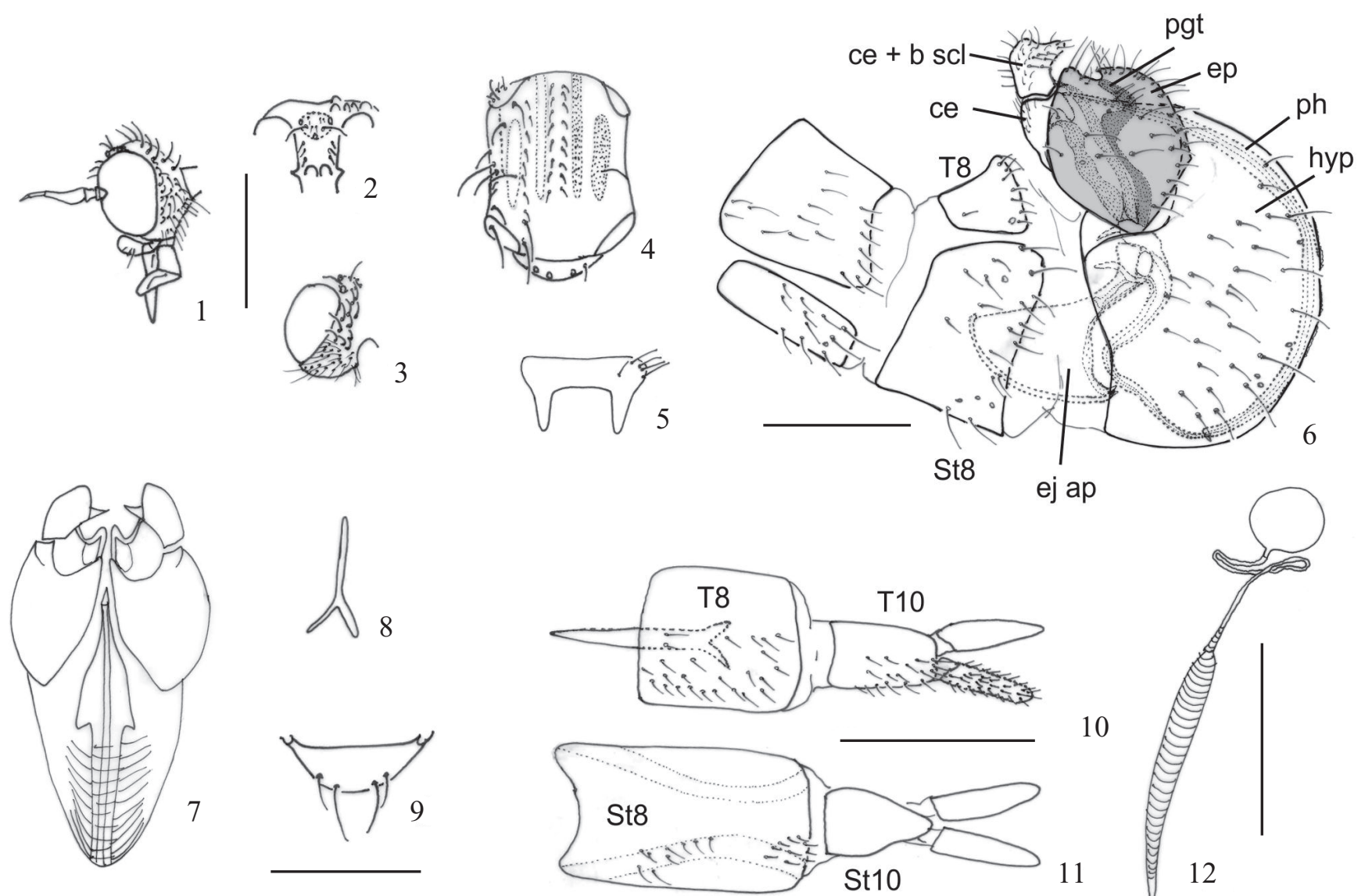

Legs dark brown except tibial joints of femora yellow, with distinct grey pruinosity in certain angles and with short setae, except posterodorsal setal row of fore femur slightly longer; mid femur with 1 anterior seta at basal third also slightly longer. Femora, especially fore and mid femora, basally swollen, as in figures 15 and 16 of $A$. nitida. First fore tarsomere thicker than tibia, as in figure 15 of $A$. nitida.

Wing (Fig. 49) hyaline with pterostigma pale yellow, inconspicuous; vein $\mathrm{R}_{4+5}$ slightly swollen; costal vein with robust basal seta. Halter pale yellow.

Abdomen dark brown to dark, velvety black, with short and light-colored setae and grey pruinosity on posterior margins of tergites; lateral view almost entirely grey, in posterior view almost entirely matte black; tergites concolorous with each other.

Terminalia partially black, shiny dorso-apically. Tergite 8 (Fig. 5) narrow with broad incision along anterior margin. Sternite 8 larger than corresponding tergite. Cercus and lobe formed by cercal plate + bacilliform sclerite separated by weak line. Epandrium (Fig. 6) small, with small posterodorsal cleft. Hypandrium large, keel-shaped, in posterior view as in Fig. 7. Postgonite sinuous. Ejaculatory apodeme (Fig. 8) large and trilamellar, with short ventral expansions.

Figs. 1-12. Atrichopleura crassa Bezzi. 1-9, male lectotype (pres. desig.). 1, head, lateral view; 2, frons, front view; 3, head, posterolateral view; 4, thorax, dorsal view; 5 , tergite 8 , dorsal view; 6 , terminalia, lateral view; 7 , terminalia, posterior view; 8 , ejaculatory apodeme shape, posterior view. 9-12, female paralectotype. 9, scutellum, dorsal view; 10, abdominal segments 8, 10 and cercus, dorsal view; 11, abdominal segments 8 , 10 and cercus, ventral view; 12, duct and spermathecal receptacle. Abbreviations: $c e=$ cercus, ce $+\mathrm{b}$ scl $=$ cercus + bacilliform sclerite, ej ap $=$ ejaculatory apodeme; ep $=$ epandrium, hyp $=$ hypandrium, $\mathrm{ptg}=$ postgonite; $\mathrm{ph}=$ phallus, $\mathrm{St}=$ sternite, $\mathrm{T}=$ tergite. Scales: $1-4,9=0.5 \mathrm{~mm}, 6-7,10-11=0.2 \mathrm{~mm}, 12=0.1 \mathrm{~mm}$. 
Female: similar to male, except fore tarsomere simple. Scutellum with longer apical setae, slightly convergent (Fig. 9). Abdomen velvety matte black with narrow grey pruinosity on posterior margins of tergites, in dorsal view entirely matte black.

Terminalia with tergite 8 shorter than sternite 8 (Figs. 10, 11), latter with more sclerotized lateral bands (Fig. 11). Spermatheca with duct diameter wider at base and then narrowing until reaching spherical receptacle (Fig. 12).

Geographic distribution. Chile.

Material examined. CHILE [Valparaiso], Quillota, 20.ix.1902 [1000 $\mathrm{m}]$ (male lectotype, female paralectotype, here designated).

Lectotype condition. Right foreleg, left midleg and both hindlegs are missing; right wing on microslides. Terminalia in small bottle with glycerin.

\section{Atrichopleura nitida Bezzi}

(Figs. 13-23, 50-51)

Atrichopleura nitida Bezzi, 1909: 358; Melander, 1928: 134; Collin, 1933: 196 (cit); Smith, 1967: 32 (cat), Yang et al., 2007: 204 (cat).

Diagnosis. Body shiny black. Postcranial bristles more robust in upper half. Outer vertical setae subequal to inner vertical setae. Proboscis small, slightly curved. Two pairs of scutellar setae. Femora basally swollen. Male first fore tarsomere thicker than tibia. Sc vein incomplete. $\mathrm{A}_{1}$ vein evanescent. Halter milky white.

Redescription. Lectotype male (pres. desig.). Body 3.0 $\mathrm{mm}$, wing $3.0 \mathrm{~mm}$ long.

Head (Fig. 13) dichoptic. Frons dark brown to black, shiny, sparsely grey pruinose in certain angles, about 1.5 times higher than wide, with 3-4 small lateral proclinate setae. Face glabrous, concolorous with subquadrate frons, slightly divergent toward proboscis. Palpus brown at base, yellow and globular at apex. Proboscis black and shiny, smaller than height of head, slightly curved. Ocellar triangle slightly protruding, with anterior ocellar setae divergent and 2-3 small posterior setae. Ocelli yellow. Antenna missing. Postcranium black, grey pruinose with black setae; postocular setae aligned on upper half and occipital setae misaligned on lower half, distinctly more slender and clear. Gena and postgena with slender, long and clear setae.

Thorax (Fig. 14) shiny black, with grey pruinosity mainly on pleura, except for anepisternum, katepisternum and anepimeron predominantly shiny with grey pruinosity at level of sutures. Chaetotaxy: 1 antepronotal black, lateral and distinct; 5-7 postpronotals, one slightly more robust, at least 1

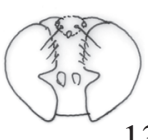

13
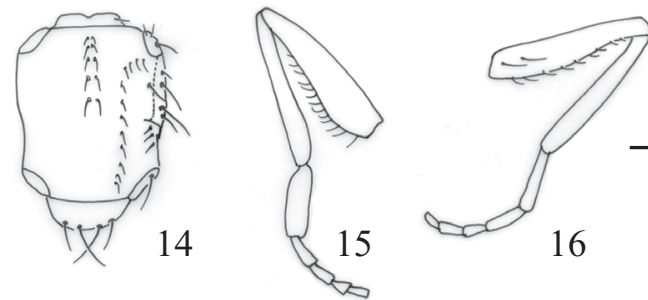

16
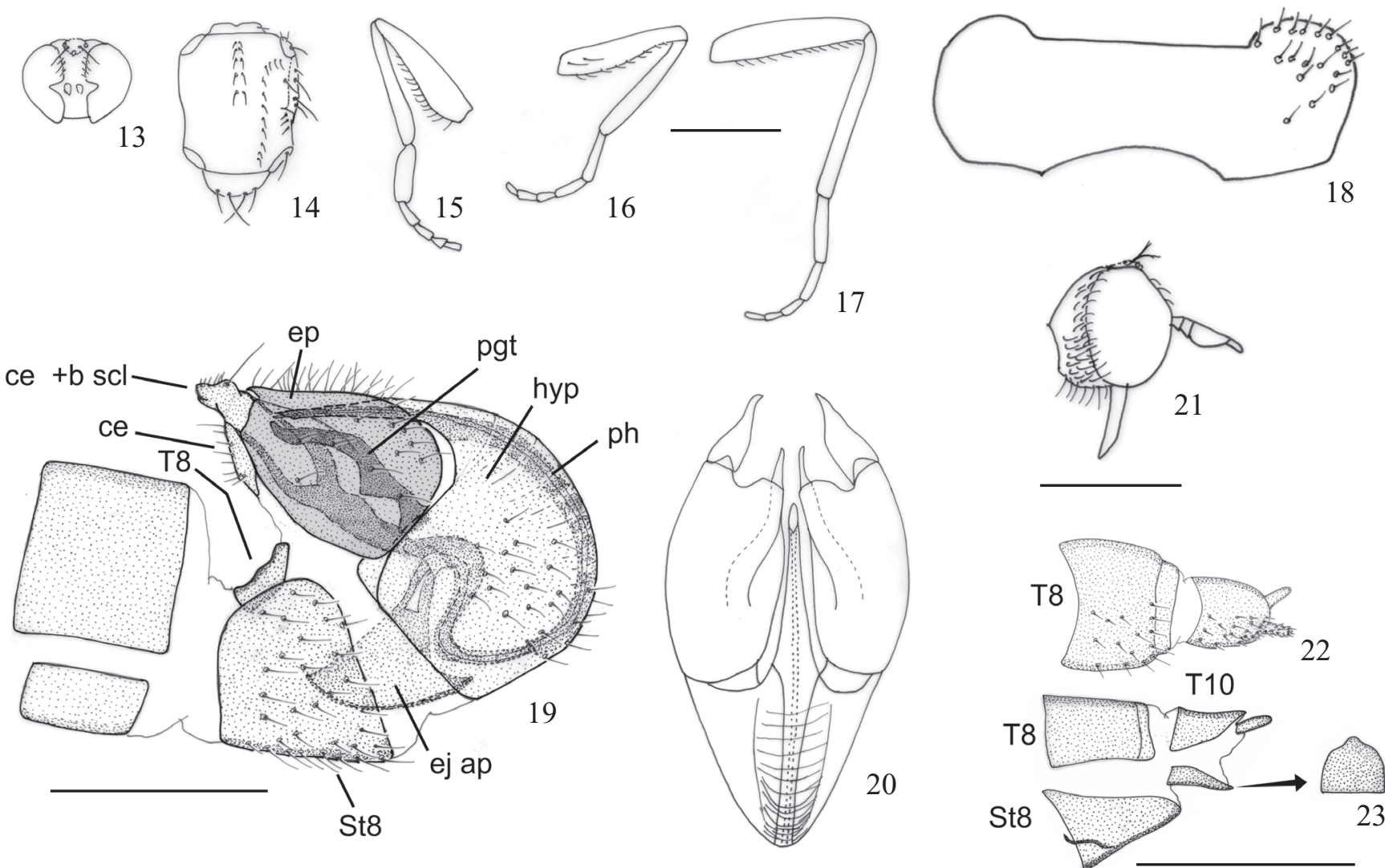

Figs. 13-23. Atrichopleura nitida Bezzi. 13-20, male lectotype (pres. desig.). 13, head, frontal view; 14, thorax, dorsal view; 15, right fore leg, posterior view; 16, left mid leg, anterior view; 17, left hind leg, anterior view; 18, tergite 8, dorsal view; 19, terminalia, lateral view; 20 , terminalia, posterior view. 21-23, female paralectotype. 21, head, lateral view; 22, abdominal segments 8, 10 and cercus, dorsal view; 23, abdominal segments 8 , 10 and cercus, lateral view showing detail of sternite 10 in ventral view. Abbreviations: $c e=$ cercus, $c e+b$ scl $=$ cercus + bacilliform sclerite, ej ap $=$ ejaculatory apodeme; ep $=$ epandrium, hyp = hypandrium, $\mathrm{ptg}=$ postgonite $; \mathrm{ph}=$ phallus, $\mathrm{ST}=$ sternite, $\mathrm{T}=$ tergite. $\mathrm{Scales}: 13-17,21=0.5 \mathrm{~mm} ; 18-20,22-23=0.2 \mathrm{~mm}$. 
slender proepisternal; several short and clear proepimerals, 5 uniseriate presutural acrostichals; about 10 uniseriate dorsocentrals, and 2-3 intra-alar presuturals; 1 robust supra-alar presutural, 3 supra-alar postsuturals; 1 robust postalar; 3 notopleurals, with 1-2 slender; 2 scutellars, with apical pair crossed.

Legs black, shiny with short setae, except slightly longer anteroventral and posteroventral rows on all femora. Foreleg (Fig. 15) with basal portion of femur swollen and basitarsomere slightly thicker than tibia. Mid femur (Fig. 16) with basal portion more swollen than apex, bearing 2-3 anterior setae longer on basal third. Hind leg (Fig. 17) longer than anterior two pairs.

Wing (Fig. 50) hyaline with brown pterostigma at apex of vein $R_{1}$. Vein $R_{4+5}$ slightly curved subapically. Base of costal vein with one robust seta. Halter milky white.

Abdomen shiny black, with short clear setae. Tergites concolorous with sternites. Tergite 8 smaller than corresponding sternite (Fig. 19), slightly projected posterolaterally (Fig. 18).

Terminalia keel-shaped, projected upward and forward (Fig. 19); in posterior view as in Fig. 20. Tergite 8 smaller than corresponding sternite, slightly projected posterolaterally (Fig. 18). Cercus and lobe formed by cercal plate + bacilliform sclerite somewhat fused together. Postgonite slightly curved apically (Fig. 19). Ejaculatory apodeme lamellar.

Female: similar to male except fore tarsomere simple. Antenna matte black and velvety. Postpedicel (Fig. 21) two times longer than length of scape and pedicel combined; stylus broken. Wing as in Fig. 51. Terminalia (Figs. 22-23) with short cercus.

Geographic distribution. Peru.

Material examined. PERU [Cuzco], Sicuani, 08.vi.1903 [3500 m] (lectotype male, 2 paralectotype males); 07.vi.1903 (3 paralectotype males); 09.vi.1903 (2 paralectotype males, one paralectotype female). Lectotype and paralectotypes here designated.

Lectotype condition. postpedicel lost; right wing in microslides; terminalia in microvial with glycerin.

\section{Atrichopleura hirtipes Bezzi}

(Figs. 24-32, 52)

Atrichopleura hirtipes Bezzi, 1909: 361; Melander, 1928: 134; Collin, 1933 : 196 (cit); Smith, 1967: 32 (cat), Yang et al., 2007: 204 (cat).

Diagnosis. Dark brown to black, sub-shiny; legs brown with yellow coxae and trochanters. Frons with long setae, one of them subequal to ocellar setae. Face pilose with small setae. Outer vertical setae long and proclinate, extending over the eye. Scutellum with three pairs of setae. Fore and mid tibiae with long setae, which also are present on their basal tarsomeres, but shorter. Sc vein nearly complete. A, vein distinct. Tergites with robust uniseriate setae on posterior margins.

Redescription. Lectotype male (pres. desig.). Body 3.5 $\mathrm{mm}$, wing $4.4 \mathrm{~mm}$ long.

Head (Fig. 24) dichoptic. Frons (Fig. 25) wider than ocellar triangle, slightly higher than wide, grey pruinose in fron- tal view, velvety matte brown in dorsal view. Four lateroclinate frontal setae, one of them long and subequal to ocellar setae. Face wide, same height as frons, widened toward proboscis, grey pruinose with 2-3 lateral setae, small and proclinate. Ocellar triangle slightly protuberant, with long lateroclinate anterior ocellar setae and 3-4 relatively long posterior setae. Ocelli yellow, glassy. Postcranium dark brown and slightly grey pruinose, with distinct setae, long and concolorous with each other. Inner vertical and outer vertical setae elongate, notably the latter moved laterally, longer than ocellar setae and extending over eye. Occipital setae multiseriate, arranged in almost regular rows (Fig. 24). Gena and postgena with several setae similar to occipital setae. Palpus brown with darker apex, clothed in long setae. Proboscis shorter than height of head, straight, with shiny brown labrum, some areas black, otherwise light brown. Antenna velvety matte black, with scape and pedicel brownish. Postpedicel 1.5 times longer than length of scape and pedicel combined, and 1.5 times longer than stylus (Fig. 24).

Thorax dark brown to black, grey pruinose; in dorsal view with longitudinal band of reddish-brown pruinosity between acrostichal and dorsocentral setae and between dorsocentral and supra-alar setae (Fig. 26). Anepimeron, katepisternum and katepimeron partially yellow-brown in certain angles. Larger thoracic setae black; smaller setae clear. Chaetotaxy: 3-4 antepronotal laterals; 1 postpronotal robust and several slender setae; 1 proepisternal; several proepimeral short, about 10 acrostichals uniseriate, about 12 uniseriate dorsocentrals, posterior more robust; 1 intra-alar presutural robust and several more slender, 2-3 intra-alar postsutural in transverse row near transverse suture; 1 supra-alar presutural robust and 3-4 slender setae, 4 supra-alar postsuturals, posterior one robust; 1 notopleural robust and several of unequal sizes; 1 postalar, 3 pairs of scutellars, apical pair crossed or nearly so.

Legs brown except coxae, trochanters and base of tibiae yellow. Femora with rows of longer anteroventral and posteroventral setae. Mid femur with anterior row of long setae. Fore (Fig. 27) and mid tibiae (Fig. 28) with long dorsal, anterodorsal and posterior setae; basal tarsomeres with shorter setae on dorsal face. Hind leg (Fig. 29) longer and more slender than other legs, with dorsal setae longer at tibia.

Wing (Fig. 52) long, slightly brownish, with inconspicuous pterostigma. Sc vein complete; vein $\mathrm{R}_{4+5}$ almost straight; vein $\mathrm{A}_{1}$ distinct. Halter with yellow stem and brown capitulum.

Abdomen dark brown to black (Fig. 30), with grey-brown pruinosity in anterior view, with long clear setae, except posterior margin of tergites with long black uniseriate setae. Tergites concolorous with sternites. Tergite 8 small.

Terminalia (Figs. 31-32) keel-shaped, with long setae. Epandrium high and narrow, with pointed and more sclerotized apex. Cercus divided into two lobes. Cercus + internal bacilliform sclerite placed internally to epandrium apex, hardly visible. Hypandrium with very long posteroventral setae. Postgonite elongate, thin and recurved. Ejaculatory apodeme lamellar. 


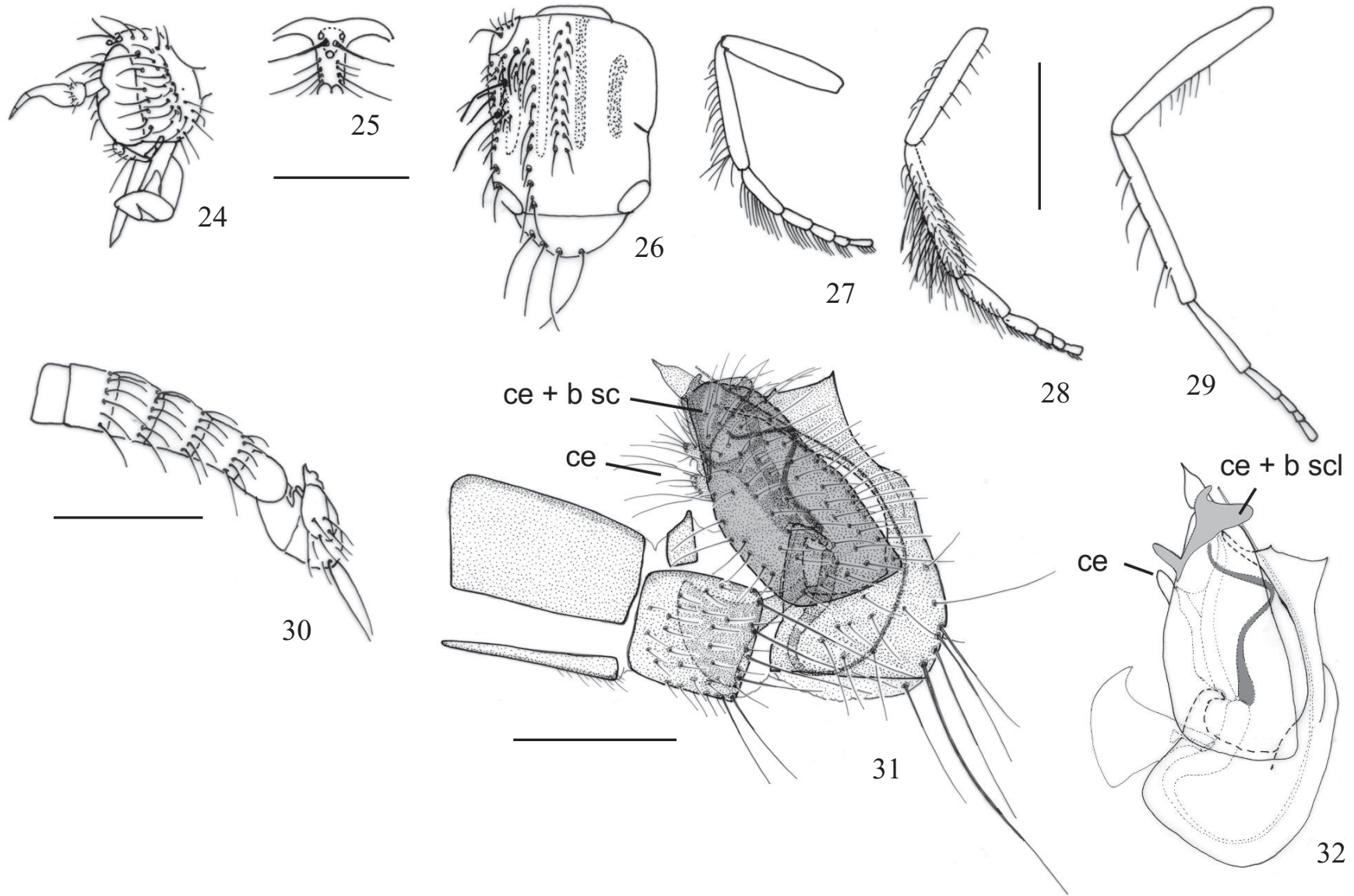

Figs. 24-32. Atrichopleura hirtipes Bezzi, male lectotype (pres. desig.). 24, head, lateral view; 25, frons, frontal view; 26, thorax, dorsal view; 27, left fore leg, posterior view; 28, left mid leg, posterior view; 29, right hind leg, anterior view; 30, abdomen, lateral view; 31, terminalia, lateral view; 32, terminalia epandrium removed, lateral view. Abbreviations: $\mathrm{ce}=$ cercus, $\mathrm{ce}+\mathrm{b} \mathrm{scl}=$ cercus + bacilliform sclerite. Scales: $30=1 \mathrm{~mm}, 24-26,27-29=0.5 \mathrm{~mm}, 31-$ $32=0.1 \mathrm{~mm}$.

Female: not studied. Originally described as: "legs without long setae, terminalia protracted with elongated apical lamella".

Geographic distribution. Peru.

Material examined. PERU [Cuzco], Larestal (= Paso de Lares), 08.viii.1903, 3000-4000 m (lectotype male, here designated).

Lectotype condition. Right wing in microslides. Terminalia in microvial with glycerin.

\section{Atrichopleura schnusei Bezzi}

(Figs. 33-41, 53)

Atrichopleura schnusei Bezzi, 1909: 362 (part.); Melander, 1928: 134; Collin, 1933: 196 (cit); Smith, 1967: 32 (cat); Yang et al., 2007: 204 (cat).

Diagnosis. Dark brown to black, sub-shiny; legs lighter, brown. Frons and face with distinct setae. Scutellum with three pairs of setae. Male foretibia clavate, with tuft of long setae on distal half. Fore basitarsomere thicker than tibia in both sexes. Sc vein complete. A, vein evanescent. Phallus long and slender.

Redescription. Lectotype male (pres. desig.). Body 3.2 $\mathrm{mm}$, wing $4.0 \mathrm{~mm}$ long.
Head dichoptic, lower facets slightly larger. Frons slightly narrower than ocellar triangle, somewhat higher than wide, with sparse grey pruinosity in frontal view and sparse brown pruinosity in dorsal view. 3-4 frontal setae lateroclinate, one of them longer, but smaller than ocellar setae. Face as high as frons, wide, divergent toward proboscis, grey pruinose, and with 2-3 lateral small and proclinate setae. Ocellar triangle slightly protuberant with long anterior lateroclinate ocellar setae and at least one distinct posterior, small seta. Ocelli yellow, glassy. Outer vertical setae laterally displaced and subequal to ocellar setae, proclinate above eye. Postcranium dark brown, slightly grey pruinose, with distinct slender brown setae, concolorous with each other. Occipital setae multiseriate and misaligned. Gena and postgena with several setae similar to occipital setae. Palpus brown with darker apex and long setae. Proboscis shorter than height of head, straight, with brown and shiny labrum. Antenna velvety matte black, with scape and pedicel slightly brown. Postpedicel 2 times longer than length of scape and pedicel combined, and 1.5 times longer than stylus.

Thorax dark brown to black, sub-shiny, sparsely grey pruinose. All setae yellowish-brown: 2-3 antepronotals placed laterally; 1 postpronotal robust and $4-5$ slender setae; 1 

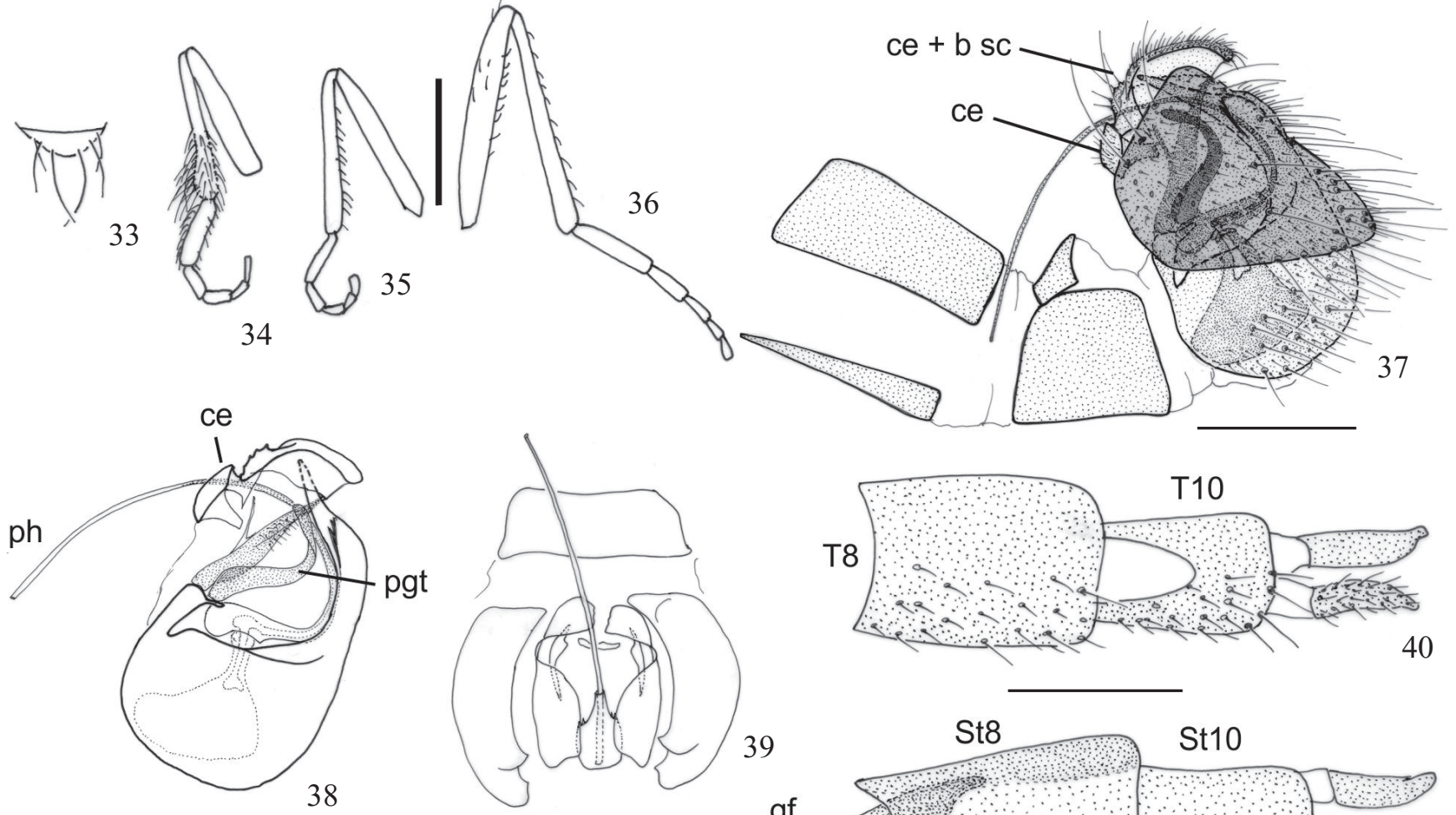

\section{9}

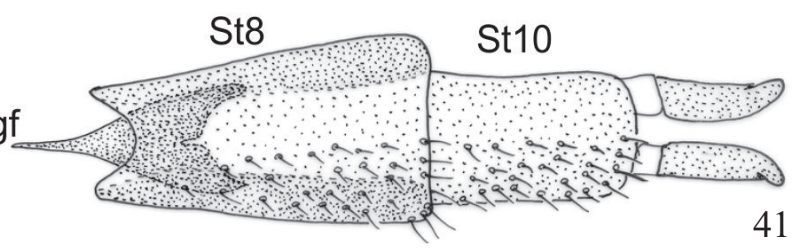

Figs. 33-41. Atrichopleura schnusei Bezzi, male lectotype (pres. desig.). 33, scutellum, dorsal view; 34, left fore leg, posterior view; 35, left mid leg, posterior view; 36, left hind leg, anterior view; 37, terminalia, lateral view; 38, terminalia, removed epandrium and setae, lateral view; 39, terminalia, posterior view. 40-41, female paralectotype. 40, abdominal segments 8,10 and cercus, dorsal view; 41, abdominal segments 8,10 and cercus, ventral view, also showing the genital fork. Abbreviations: $\mathrm{ce}=$ cercus, $\mathrm{ce}+\mathrm{b} \mathrm{scl}=$ cercus + bacilliform sclerite, $\mathrm{gf}=$ genital fork, $\mathrm{ptg}=$ postgonite; $\mathrm{ph}=\mathrm{phallus}$, $\mathrm{ST}=$ sternite, $\mathrm{T}=$ tergite. Scales: $33-36=0.5 \mathrm{~mm}, 37-39,40-41=0.2 \mathrm{~mm}$.

proepisternal; several short proepimerals, about 10 uniseriate acrostichals; about 12 uniseriate dorsocentral, posterior setae more robust; 1 robust and 2-3 slender presutural intraalars; 2-3 intra-alar postsuturals in transverse row next to transverse suture; $3-4$ supra-alar presuturals, 1 slightly more robust; 3 postsutural supra-alar, 1 of them robust; 1 robust notopleural and many setae of unequal sizes; 1 postalar; 3 pairs of scutellars, apical pair crossed (Fig. 33).

Legs brown, darker from tibiae. Femora slender, with longer anteroventral and posteroventral rows of setae. Fore tibia (Fig. 34) clavate distally with tuft of long posterodorsal, posterior and posteroventral setae on distal half; fore basitarsomere slightly thicker than remaining tarsomeres. Mid femur (Fig. 35) with anterior row of long setae. Hind leg (Fig. 36) longer and more slender than anterior legs, with dorsal setae of tibia slightly longer.

Wing (Fig. 53) hyaline, long, brownish, with brown pterostigma. Sc vein almost complete, apparently touching costal vein; vein $R_{4+5}$ vein curved; vein $A_{1}$ distinct. Halter with yellow stem and brown capitulum.

Abdomen brown, grey-brown pruinose, with distinct yellowish-brown setae. Tergites 5-6 with long uniseriate setae on posterior margin. Sternites concolorous with tergites. Ter- gite 8 small. Terminalia (Figs. 37-39). Cercus and lobe formed by cercal plate + sclerite bacilliform separated by line of weakness. Epandrium with posteroventral portion rather acute (Fig. 37). Phallus very long and slender (Fig. 38). Hypandrium with slender setae, subequal in length. Postgonite curved. Ejaculatory apodeme lamellar.

Female. Differs from male by unmodified legs, fore tibia slender and lacking tuft of setae; abdomen without robust setae on posterior margin of tergites. Terminalia (Figs. 4041) with basal incision in tergite 10 (Fig. 40), sternite 8 more sclerotized laterally (Fig. 41), cercus small, slightly acuminate distally. Genital fork (Fig. 41) with apical and short lateral processes.

Geographic distribution. Chile.

Material examined. CHILE, Valparaiso, 12.ix.1902 [3400 m] (lectotype male, 5 paralectotype males, and 1 paralectotype female). Lectotype and paralectotypes here designated.

Lectotype condition. Right wing in microslides. Terminalia in microvial with glycerin. Remarks. One specimen with yellow legs, basal tarsomere more swollen, pterostigma more conspicuous, and different terminalia, belonging to a previously undescribed species, described below. 


\section{Atrichopleura bezzii sp. nov.}

(Figs. 42-48)

Atrichopleura schnusei Bezzi, 1909: 362 (part.).

Diagnosis. Dark brown to black, sub-shiny. Postocular setae subequal to occipital setae. Legs and halter yellow. Frons and face with setae. Scutum robust, setae little differentiated. Fore tibia clavate, with long setae dorsally. Abdomen with yellowish-brown setae. Vein Sc nearly complete. Vein $\mathrm{A}_{1}$ distinct.

Description. Holotype male. Body $3.2 \mathrm{~mm}$, wing $3.3 \mathrm{~mm}$ long.

Head dichoptic, lower facets slightly larger. Frons slightly narrower than ocellar triangle, slightly higher than wide, sparsely grey pruinose. Frons with 3 black lateroclinate setae subequal in length, smaller than anterior ocellar setae. Face 1.5 times higher than frons and two times higher than greatest width, slightly widened toward proboscis, grey pruinose and with 4-5 lateral, slender and clear setae. Ocellar triangle slightly protuberant, with long lateroclinate anterior setae and 2-3 small posterior setae. Ocelli yellow and glassy. Postcranium dark brown with grey pruinosity, with distinct long brown setae concolorous with each other. Postocular and occipital setae subequal in length. Gena and postgena with several setae similar to occipital setae. Palpus curved upwards, slightly darker yellow on apex, with long setae. Proboscis shorter than height of head, straight, with shiny black labrum. Antenna with brown scape and pedicel (postpedicel and stylus lost).

Thorax dark brown to black, sub-shiny, sparsely grey pruinose, with brighter faint reddish-brown longitudinal band between acrostichal and dorsocentral setae and inconspicuous band between dorsocentral and supra-alar setae. All setae yellowish brown. Chaetotaxy: 2-3 lateral antepronotals; 1 robust postpronotal and several slender setae; $3-4$ inconspicuous proepistenals; several short proepimeral; about 10 uniseriate acrostichals; about 12 uniseriate dorsocentrals, posterior setae more robust; short presutural intra-alars; postsutural intra-alars not observed; 3-4 short presutural supra-alars; 3 postsutural supra-alars, posterior seta robust; 2 robust notopleurals and several slender setae; 1 postalar; 3 pairs of scutellars, with apical pair crossed.

Legs yellow with darker fore tarsus. Femora with anteroventral and posteroventral rows of long slender setae. Mid femur with anterior row of long slender setae. Fore leg (Fig. 42) with clavate tibia, bearing long setae along entire anterodorsal, dorsal and posterodorsal faces; basitarsomere quite swollen, wider than tibia. Hind leg longer and more slender than anterior legs, with dorsal setae slightly longer at apex of tibia.
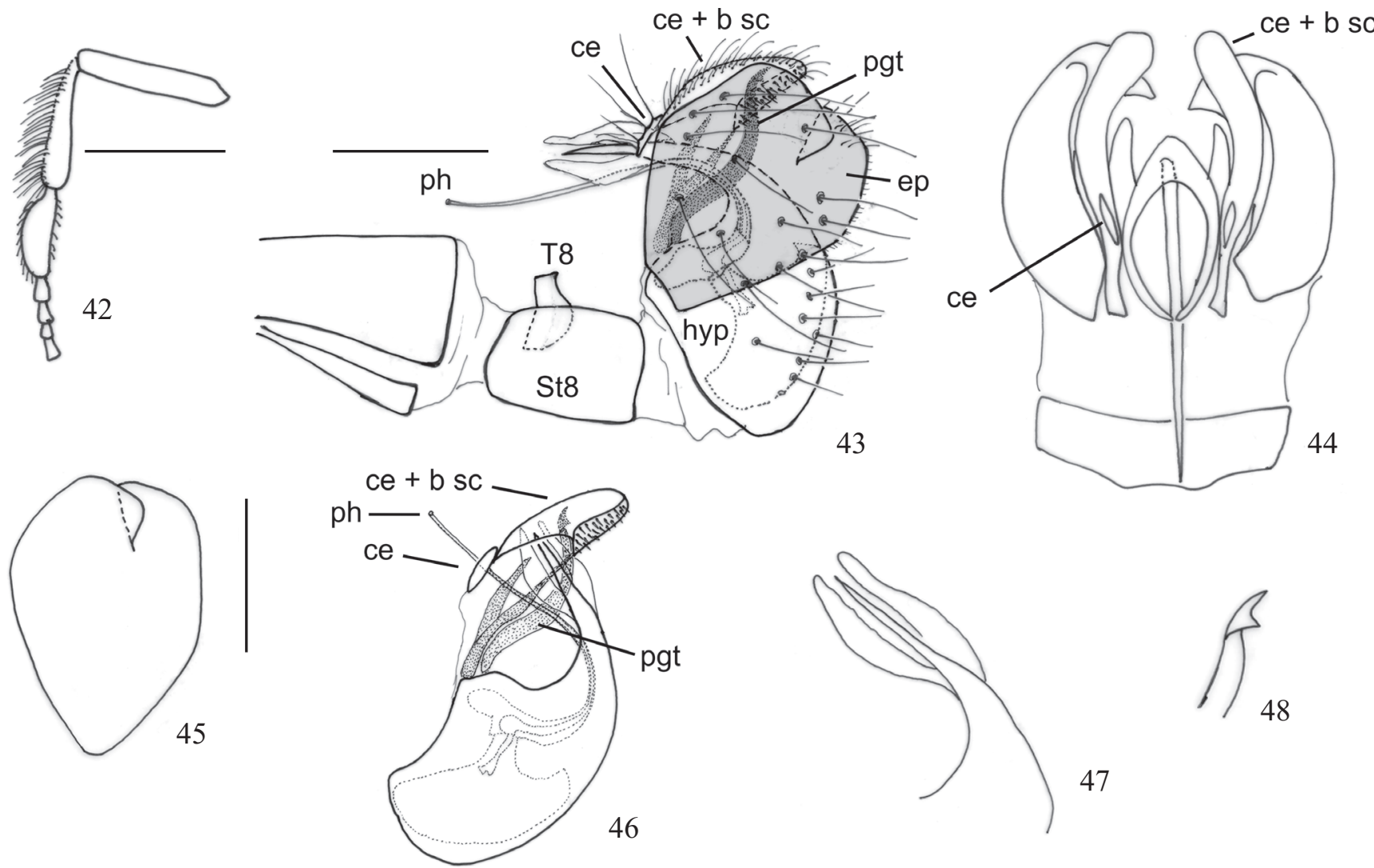

43

Figs. 42-48. Atrichopleura bezzii, sp. nov., male holotype. 42, left fore leg, posterior view; 43, terminalia, lateral view; 44, terminalia, dorsal view; 45, epandrium; 46, hypandrium, removed epandrium; 47, hypandrium apex, posterior view; 48, postgonite apex. Abbreviations: ce $=$ cercus, ce $+\mathrm{b}$ scl $=$ cercus + bacilliform sclerite, ep = epandrium, hyp, hypandrium, ptg = postgonite; $\mathrm{ph}=$ phallus, $\mathrm{ST}=$ sternite, $\mathrm{T}=$ tergite $\mathrm{Scales}: 42=0.5 \mathrm{~mm}, 43-48=0.2 \mathrm{~mm}$. 

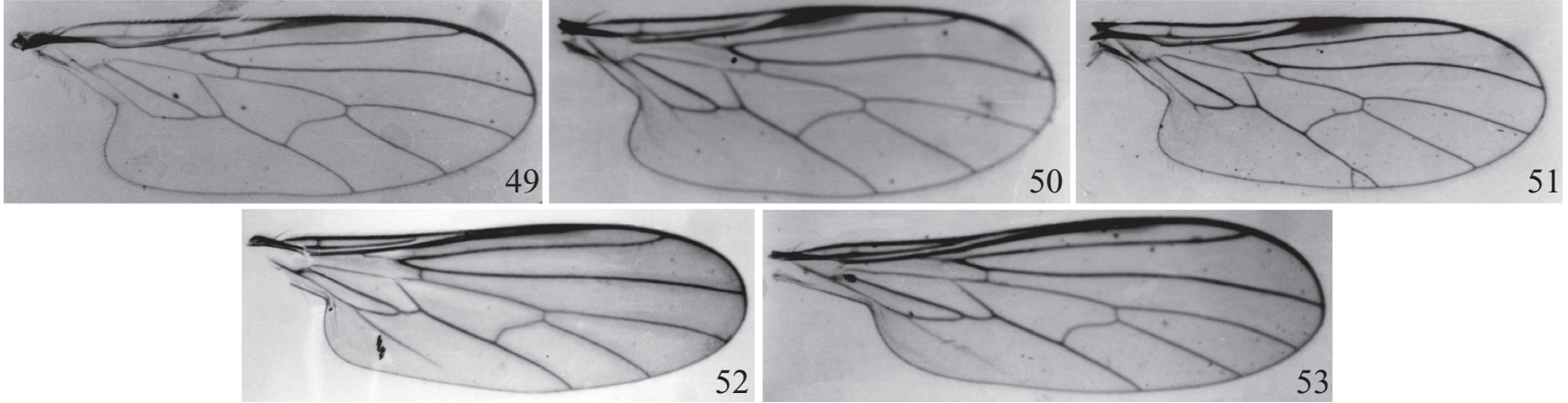

Figs. 49-53. Wings. 49, Atrichopleura crassa Bezzi, male lectotype (pres. desig.). 50, A. nitida Bezzi, male lectotype (pres. desig.) 51, A. nitida Bezzi, female paralectotype; 52, A. hirtipes Bezzi, male lectotype (pres. desig.); 53, A. bezzii, sp. nov., male holotype.

Wing (very similar to Fig. 53, A. schnusei) long, slightly brownish, with distinct brown pterostigma. Sc vein nearly complete. Vein $\mathrm{R}_{4+5}$ slightly curved aubapically. Vein $\mathrm{A}_{1}$ distinct. Halter yellow.

Abdomen brown, grey-brown pruinose. Posterior margin of tergites with narrow transverse band of grey pruinosity and distinct yellowish-brown setae. Posterior margins of tergites 5-6 with long uniseriate setae. Sternites concolorous with tergites.

Terminalia: Tergite 8 narrow when compared with sternite 8 (Fig. 43). Epandrium with small dorsal incision (Fig. 45). Cercus and lobe formed by cercal plate + bacilliform sclerite somewhat fused (Figs. 44, 46). Posterior lobe, composed of cercus + bacilliform sclerite with long ventral spiniform setae (Fig. 46). Apex of hypandrium trifid, lateral protuberances membranous (Fig. 47). Postgonite with apex slightly split (Fig. 48). Ejaculatory apodeme lamellar. Phallus long and slender (Fig. 46).

Geographic distribution. Chile.

Material examined. CHILE, Valparaiso, 12.ix.1902, [C.A.W. Schnuse] (holotype male)

Atrichopleura bezzii, sp. nov. is close to A. schnusei Bezzi. It differs by having the face longer than the frons; the scutum lacking robust setae (intra-alars absent and presutural supraalar setae distinctly more robust) and attributes of the male terminalia when comparing figure 37 with figure 43 .

\section{REFERENCES}

Bezzi, M. 1909. Beiträge zur Kenntnis der südamerikanischen Dipterenfauna auf Grund der Sammelergebnisse einer Reise in Chile, Peru und Bolivia, ausgeführt in den Jahren 1902-1904 von W. Schnuse. Nova Acta Academiae Caesareae Leopoldino-Carolinae Germanicae Naturae Curiosorum, Halle 91: 293-407.

Collin, J. E. 1933. Empididae, In: Diptera of Patagonia and South Chile. Vol. 4, London, British Museum of Natural History, 334 p.

Cumming, J. M. \& D. M. Wood. 2009. Adult morphology and terminology, p. 9-50. In: B. V. Brown, A. Borkent; J. M. Cumming; D. M. Wood; N. E. Woodley \& M. A. Zumbado (Eds.), Manual of Central American Diptera. Volume 1. Ottawa, NRC Research Press, 714 p.

McAlpine, J. F. 1981. Morphology and terminology - adults, p. 9-63. In: J. F. McAlpine F.; B. V. Peterson; G. E. Shewell; H. J. Teskey; J. R. Vockeroth \& D. M. Wood (Eds.). Manual of Nearctic Diptera, Vol. 1, Research Branch, Agriculture Canada, Monograph 27, 674 p.

Melander, A. L. 1928. Diptera, Fam. Empididae. In: P. Wystman (Ed.). Genera Insectorum 185: 1-434, plates 1-8

Rafael, J. A. \& R. Ale-Rocha. 1995. Revisão das espécies neotropicais de Empididae (Diptera) descritas por Mario Bezzi. I. Hybotinae. Revista Brasileira de Entomologia 39: 517-546.

Rafael, J. A. 2011. Revisão das espécies neotropicais de Empididae (Diptera) descritas por Mario Bezzi. VII. As espécies descritas em Hilara Meigen. Revista Brasileira de Entomologia 55: 317-326.

Sinclair, B. J. \& J. M. Cumming. 2006. The morphology, higher-level phylogeny and classification of the Empidoidea (Diptera). Zootaxa 1180: 1-172.

Smith, K. G. V. 1967. Family Empididae (Empidae, Hybotidae). In: A Catalogue of the Diptera of the Americas South of the United States. Vol. 39, São Paulo, Secretaria da Agricultura do Estado de Sao Paulo, 67 p. Yang, D.; K. Zhang; G. Yao \& J. Zhang. 2007. World Catalog of Empididae (Insecta: Diptera). Beijing, China Agricultural University Press, 599 p.

Received 20/4/2011; accepted 8/12/2011

Editor: Silvio Shigueo Nihei 